\section{BRITISH SCIENTIFIC INSTRUMENTS}

\section{PHYSICAL SOCIETY'S EXHIBITION}

$\mathrm{T}$ HE healthy condition of the British scientific instrument industry was again demonstrated at the second post-war exhibition held by the Physical Society at the Imperial College of Science and Technology, South Kensington, at Easter. In the past it has been customary to hold the exhibition early in January, but owing to the extraordinary and unforeseen large increase in attendance at the first post-war exhibition (held January 1946), it became necessary to make fresh arrangements. These took the form of a restriction in the number of tickets issued (limited to about 12,000), an increase of the floor space of the exhibition (extending into a part of the Science Museum), and an increase in the period during which the Exhibition was open, from three to four days (April 9-12 inclusive). It was mainly due to this latter change that the Exhibition, the thirty-first of the series, was held at Easter instead of the New Year. These changes certainly had the desired effect, and visitors this year were able to view the splendid display of scientific instruments under relatively comfortable conditions.

Owing to paper supply and printing difficulties arising from the fuel crisis, it was not possible to produce the catalogue in time for the Exhibition. Consequently, a concise 8-page guide was issued for the convenience of visitors to the Exhibition, followed afterwards by the catalogue itself, a wellillustrated volume of about 380 pages. This catalogue is much more than a guide to the Exhibition : it is, in fact, a work of reference containing descriptions of a very large number of scientific instruments manufactured in Great Britain during recent years.

The Exhibition was a tribute to the high degree of skill and ingenuity shown in the design and manufacture of high-class scientific instruments in Britain. As in previous years, it was divided into two main sections, namely, the Trade Section and the Research and Educational Section. The Trade Section included exhibits from 118 firms of instrument makers, while the Research and Educational Section was represented by twenty-nine organisations, many of these being Government research establishments. During the Exhibition, four discourses were given on recent advances in various aspects of the development of scientific instruments. One of these, given by Dr. Edward Lee (of Admiralty Research Laboratory, Teddington), dealt with the development of certain types of Service infra-red equipment which has in post-war years found valuable applications in research and industry. $\mathrm{H}_{\Theta}$ dealt in particular with the image-converter tube in which infra-red radiation up to a wave-length of $1 \cdot 3 \mu$ is transformed into visible radiation. During the discourse the audience were supplied with the Service type of this tube (the R.G. tube) enabling them to see demonstrations of various interesting infra-red phenomena. Dr. Lee referred also to recent progress in the production of lead sulphïde photo-conducting cells sensitive up to a wave-length of $3 \cdot 5 \mu$. These cells have been used recently in observing transient low-temperature effects which were previously undetectable. He referred to the use of infra-red equipment fitted to military vehicles for driving at night and to the detection of the exhausts of enemy aircraft.

Interesting and instructive discourses were also given on "Recent Advances to Optical Science" and on "Air Photography" by Mr. B. K. Johnson (Imperial College) and by Mr. A. C. Brock (Royal Aircraft Establishment, South Farmborough) respectively. Prof. A. Porter in his discourse dealt with the important subject of "Automatic and Manual Position Control Systems". His remarks were based on various mechanical aspects of fire control and radar systems as used in the Services. He was mainly concerned with a discussion of the relative effects of inertia and damping in follow-up mechanisms, and the introduction of controls including the first and second differentials of displacement.

These discourses are not only of interest to the specialists but have also a more general appeal, and are now one of the important features of the Exhibition. Another feature which is gradually assuming greater importance is the exhibition of scientific and educational films. One of these, of more popular interest, was a 50 -min. film depicting episodes in the life of Lord Kelvin. The British Kinematograph Society showed ten films illustrating the uses of motion pictures in -scientific research; for example : (1) kine radiograph of normal human joints ; (2) superslow motion of a splash ; (3) films in aircraft research, etc. Another film, shown by Kodak, Ltd., Research Laboratories, illustrated the use of the phase-contrast microscope in biological studies.

In a brief review of the Exhibition, it is almost impossible to select even a representative sample of the very numerous exhibits for reference. The following, taken almost at random, may, however, serve as a rough indication of the type of exhibits to be seen. Microscopes, for example, in recent years seem to be departing more widely from the old conventional forms. In the Research Section was shown a reflecting microscope having a numerical aperture of 0.98 , with exact focal achromatism, fitted with phase-contrast illumination. Using this instrument, photomicrographs of stained and unstained material (by phase contrast) were shown. Another microscope, of an entirely different type, is the electron microscope. This has now been used in a 'shadow casting' method. Shadow-casts are formed by irradiating a supported specimen obliquely, in vacuo, with a stream of gold molecules. Such objects when viewed by transmission in an electron microscope show shadows and gradations of density in a pattern which indicates the detailed shape of the original specimen. A $50 \mathrm{kV}$. electron microscope, giving total magnifications of the order of 20,000 times, was on view in the Trade Section. of the Exhibition. The resolving power of the instrument was stated to be better than $100 \mathrm{~A}$.

Reference has been made to infra-red sensitive cells in Dr. Lee's discourse. The characteristics of lead-sulphide cells as applied to high-speed lowtemperature pyrometry were shown in the Research Section. One exhibit demonstrated the quick response-time of the lead sulphide cell, about 20 microsec. at room temperature. At the peak of its sensitivity curve $(2 \cdot 7 \mu)$, it is almost a hundred times as sensitive as the best thermocouple. At liquid-air temperatures its sensitivity is greatly increased, but its response time is now of the order 500 microsec. In addition to its use in spectroscopy, the lead sulphide cell is finding many applications in industrial processes and in research.

Developments in electrical (and electronic) instruments are particularly noteworthy, and more 'Service' applications were released in time for this Exhibition. One form of bomb locator which was exhibited was 
in principle a very sensitive magnetometer for measuring the distortion of the earth's magnetic field due to the presence of ferro-magnetic material. The sensitive element in this locator is a length of mu-metal wire, the A.C. resistance of which varies with the field along the axis of the wire. Variation of the resistance is indicated by a sensitive bridge circuit. Two widely spaced elements are used to indicate the field gradient.

Perhaps one of the most popular and striking exhibits was the demonstration of centimetre waves and the equipment used in the generation, transmission and reception of centimetre waves. Wave guides, magnetrons, klystrons, dielectric rod and tube aerials, lens-corrected horns, crystal receivers, concentric probes, bolometers for power measurement, polarization-plane changers, etc., for use in micro-wave communications and research were to be seen on several stands both in the Trade and Research Sections. Demonstrations were given illustrating the properties of centimetre waves such as reflexion, focusing, stationary waves, polarization and attenua. tion.

In the Trade Section a cathode ray tube known as the 'Skiatron' was demonstrated. In this tube the electrons, instead of causing fluorescence when they strike the screen, produce an image of varying opacity which can be projected on a screen, using conventional sources of high-intensity illumination, instead of relying on the relatively weak illumination produced on a fluorescent screen.

Another interesting exhibit in the Trade Section was the equipment used in picture telegraphy. This equipment was designed primarily for use by the Press for the transmission of news-pictures directly over existing telephone networks, or in conjunction with radio links. The commercial applications are obvious, and the system offers possibilities in crime detection, since it permits of rapid transmission of finger-prints and other pictorial matter. The definition obtained in this system is very good, and the speed of scanning satisfactory; for example, a picture 10 in. $\times 8$ in. can be transmitted in $7-20$ min., according to the scanning-line and drum speed combination.

An entirely novel feature in this year's Exhibition was the exhibit of the Atomic Energy Research Establishment (Electronics Group). Electronic $\beta$-ray counters and health monitors for $\beta$ - and $\gamma$ - and slow neutron radiations were demonstrated. Mueh interest is being taken in the design of Geiger counters and in various forms of apparatus for measuring ionization, with associated electronic equipment. Counting rates as high as 5,000 a minute are now readily obtainablethis compares very favourably with the normal rates of $20-30$ a minute when counting $\alpha$-particle scintillations by eye. The importance of the exhibit was not so much in what it actually showed as in what it foreshadowed.

In acoustics, improved types of noise meters were exhibited, and a demonstration was given of the absolute pressure calibration of a microphone by measurement of the amplitude of smoke particles. A novel application of soap films was demonstrated in gas analysis apparatus embodying a dynamic method instead of the more usual static method. The apparatus consists of eight soap film meters incorporating the necessary absorbent solutions. To carry out an analysis, which can be completed in three minutes, soap films are formed in each meter by raising and lowering valves.
The use of silicone-insulated windings in electric motors running at abnormally high temperatures was demonstrated in another research exhibit.

It is hoped that the above examples sufficiently illustrate the wide range covered by the exhibits. It is practically impossible for the normal visitor, who has only one day to spare to visit the Exhibition, to see everything. All he can do is to take a particular interest in a few items and a more general interest in some of the others - if time permits between his chance moetings with old acquaintances!

The thirty-first Exhibition was, if possible, even better than its predecessors, and the exhibition committee and officers of the Physical Society are again to be congratulated most heartily in the well-merited success of their annual effort.

\section{ACTION OF MUSTARD GAS ( $\beta \beta^{\prime}$-DICHLORODIETHYLSULPHIDE) ON NUCLEOPROTEINS}

\author{
BY Dr. I. BERENBLUM \\ AND \\ DR. R. SCHOENTAL
}

Oxford University Research Centre of the British

Empire Cancer Campaign, Sir William Dunn School of Pathology, University of Oxford

$\mathrm{E}$ ARLY studies on the reactivity of mustard gas ( $\beta \beta^{\prime}$-dichlorodiethylsulphide) with amines and amino-acids ${ }^{1,2,3}$ provided the first indication that its vesicant action might depend on a combination with protein constituents of the living cell. Additional in. direct support for such a view was the observation that respiratory and glycolytic processes of bacteria ${ }^{4}$ and of minced tumour tissue ${ }^{5}$ were inhibited by mustard gas in vitro, and that with the sulphone analogue there was inhibition of metabolism of brain tissue in vitro, representing a selective effect on the pyruvate oxidase system ${ }^{6}$. Actual evidence that mustard gas could combine with proteins became available when serum proteins were shown to acquire new antigenic properties after treatment in the cold with mustard gas? $^{7}$.

The antigenic change in serum proteins seemed too feeble, however, to account for the striking biological effects of mustard gas in vivo. It seemed desirable, therefore, to repeat the work, using skin proteins instead of serum proteins as test material. Preliminary experiments of this kind yielded, however, unexpected results.

A crude aqueous extract of rabbit skin, when shaken with mustard gas, developed a bulky protein precipitate, having a high sulphur content (thus indicating a combination of the protein with the mustard gas), and a high phosphorus content (sug. gesting that it was nucleoprotein in type). When a more purified preparation of nucleoprotein, derived from calf thymus, gave similar precipitation with mustard gas, while a number of other proteins failed to give this reaction, the originally planned (immunological) work was set aside, and the precipitation phenomenon investigated in greater detail.

Preparation of extracts : Finely minced tissue (skin or thymus) was extracted first with distilled water, and then with several lots of dilute borate buffer at $p \mathrm{H} 8 \cdot 5$. After removal of insoluble matter by 